\title{
Multi-parameter Coordinated Public School Admission Model by using Stable Marriage
}

\author{
Purba Daru Kusuma \\ Computer Engineering, Faculty of Electrical Engineering \\ Telkom University, Bandung, Indonesia
}

\begin{abstract}
School admission is a very important process in improving the education quality. Meanwhile, one problem in the school admission system is the mismatch. There are unassigned applicants and unallocated seats. In Indonesia, zone-based model is adopted in the public-school admission system. Students are assigned to their nearest school. Besides location, student's academic performance and economic level are also concerned. Based on it, this work proposes coordinated public school admission model that accommodates flexible number of the concerned parameters. It is built based on the stable marriage algorithm or the deferred-acceptance algorithm as its derivative. The proposed model is a combination between the mandatory approach and the school choice approach. The concerned parameters are school-home distance, student national exam score, school rank, applicant poor status, and applicant's preference. The simulation is conducted to investigate the performance of the proposed model compared with the previous models: the zone-based model and the two-step model. The prioritization of the concerned parameters is proven easily adjusted. The simulation result shows that in the over-demand condition, the proposed model creates higher average student national exam score and higher average school-home distance rather than the previous models. When the number of applicants is twice of the number of seats, the proposed model creates 6.6 percent higher in the average student national exam score and 71.4 percent higher in the average school-home distance. The simulation result also shows that the mismatch is solved.
\end{abstract}

Keywords-School admission; school choice; stable marriage; deferred-acceptance; education

\section{INTRODUCTION}

School admission system is an important system in the school management system [1]. The role of school admission system is allocating the available seats to the appropriate applicants. In the over-demand condition, the school admission plays as selection or sorting mechanism so that the preferred applicants are accepted while the others are rejected [2]. The problem becomes more complicated in the publicschool admission system. The public-school admission system is usually coordinated by the local government due to its responsibility in managing them [1]. The most common problem in this admission system is the mismatch between the schools and the applicants. There is possibility where there are unallocated seats in several schools in one side, and unassigned applicants in another side.

There are several conditions that make this problem happens. First, some schools are more favourite rather than the others. The favourite schools usually receive more applicants so that they face over demand condition [3]. Hart and Figalo [4] found that in Florida, schools with " $A$ " accreditation receive higher enrolment rather than schools with " $\mathrm{B}$ " or " $\mathrm{C}$ " accreditation. Hofflinger, Gelber, and Canas [5] found that parents with higher socioeconomic status prefer high performing schools in Chile. Erickson [6] noted that in the United States, parents value the school quality although it is not always the highest determinant. In the other side, the nonfavourite schools receive less applicants so that they face over-supply condition [7]. Second, several schools are in the strategic location, for example in the city central or in the middle of residential area, while several other schools are in the non-strategic area. Schools that face over-demand condition will reject the less appropriate applicants so that there are unassigned applicants. In the other side, several schools that face over-supply condition will have unallocated seats.

In Indonesia, public-school admission system is coordinated by the local government. This system adopts zone-based system so that schools prioritize students who live in the same zone [8]. This concept has several goals. The first goal is to allocate students to attend the school near their residential location so that the school-home distance and the transportation cost can be minimized [7]. The second goal is to minimize segregation among public schools so that there is not any stigma between favourite and non-favourite schools [9]. This segregation among schools has been blamed for creating inequality among schools where the favourite schools can maintain their superiority in academic performance compared with the non- favourite schools [7]. In the previous era, admission in public schools in Indonesia was based on the students' academic performance, specifically based on the students' national final exam score. High performing students tend to achieve high national exam score and have higher probability to be accepted in the favourite schools [7]. The opposite condition occurred in the non-favourite schools. Less favourite schools are almost impossible to complete the favourite ones.

Meanwhile, implementation of the full zone-based system has been criticized by some stakeholders. A strict zone-based system makes students from the outer zone are difficult to be accepted [9]. Students do not have choice although the academic performance of their in-the-zone schools is low. Besides, full zone-based system is blamed for eliminating incentive for students with high academic achievement to be accepted in the favourite schools. So, parents that are unwilling to submit to the low performance in-the-zone public 
schools, will send their children to the high-performance private schools to avoid sacrificing their children education quality [8]. Several local governments respond this problem by opening several admission channels sequentially to accommodate the academic achievement and the national regulation about zone-based system [8]. Unfortunately, this policy still cannot solve the mismatch problem.

There is a popular algorithm that was used in the school admission system. It is stable marriage algorithm [10] or in other term is deferred-acceptance algorithm [11]. In its origin, this algorithm is illustrated in the matching process between equal number of men and women [10]. In practical, this algorithm is used in the matching process between colleges and students [12] and between hospitals and residents [13]. This algorithm also has been implemented in New York school admission system [14]. To date, this algorithm has been improved widely.

Unfortunately, to be implemented in public-schools admission system in Indonesia, this stable marriage model needs to be improved. In the previous work, parameters included in the admission mechanism are the applicant's preference list and school-home distance [14]. Meanwhile, in Indonesia, there are some unaccommodated parameters. The first is the student national exam score [1]. The second is the affirmative mechanism where there should be mandatory allocation for every public school to accept students with several disadvantages, for example is student from lowincome background [1].

Based on the explanation above, it can be summarized as follows. First, the school choice approach and mandatory approach have advantages and disadvantages so that the combination between both approaches may produce better outcomes. Second, the stable marriage algorithm is potential to solve this problem. Third, existing studies or solutions in the school admission system that used stable marriage problem usually concern in one or few parameters. Fourth, to be complied with the regulation in Indonesia, the basic stablemarriage based solution should be improved.

Based on this problem, we propose coordinated student admission model for public schools. This work aims to develop school admission problem that accommodates both school choice approach and mandatory approach; and it complies with the requirements of school admission in Indonesia. This model is developed based on the stable marriage algorithm or deferred-acceptance algorithm.

Contribution of this work is as follows. Mainly, coordinated public school admission model is proposed based on the stable marriage algorithm with several advantages. First, this model guarantees that there will be no unassigned applicants in the over-supply or equal supply-demand condition. Second, this model accommodates parameters that are concerned by the stakeholders (school, family, and government): school-home distance, student national exam score, and affirmative scheme. Third, this model can be adjusted easily by every local government who is in charge in the public-schools admission process in its district. Fourth, this model simplifies the previous admission models process, both in the zone-based model [7] and the two-step model [14].
The remainder of this paper is organized as follows. In the second section, the previous literatures in the school admission, school choice, and stable marriage algorithm are explained. In the third section, the proposed model is explained. In the fourth section, the simulation work and simulation result are discussed. In the fifth section, the findings and the deeper analysis connecting the result with the previous works are discussed. In the sixth section, this work is concluded in answering the research purpose and the future research potentials are described.

\section{RELATED WORKS}

There are two models in the school admission system, especially in the public school. The first is mandatory model [14] and the second is school choice model [15]. These models are usually adopted in the elementary school to high school. In the mandatory model, students will be allocated to the public school which is near or the nearest to their home [1]. In the school choice model, students can choose schools that they prefer the most [16]. In some cases, hybrid model is implemented. In the first model, zone-based system is usually implemented. Schools prioritize the in-the-zone students [8]. If there are available seats, schools can accept students from the outer zones.

There are some supporting arguments to the mandatory model. First, schools must be attended by students which their house is near the school [17]. The goal is minimizing schoolhome distance. The short school-home distance offers some benefits. Students' travel time can be minimized so that their physical condition can be maintained to improve academic performance and risk or probability of the students for being late can be minimized too [17]. Short school-home distance also may reduce pollution and traffic congestion [17]. Second, there should be no selection to attend public schools. Schools are also forbidden to discriminate students based on their ability, for example student academic performance or family financial power [18].

In the other side, there are some supporting arguments to the school choice. The core reason is the market mechanism and competition. Competition among public schools can improve the school performance [19]. Schools are forced to improve their performance so that they are attracting enough to receive applications to fulfil their available seats [16]. In the school choice model, families are free to choose schools which are most preferred. In the common condition, schools with higher academic performance tend to receive large number of applicants so that in many cases, over-demand occurs [3]. In the over-demand situation, schools will implement selection process to accept their more preferred students and reject their less preferred ones [19]. In the other side, schools with less performance often meet over-supply condition which in the end of admission process, they still have unallocated seats. Several criteria that are often used in the selection process are student academic performance, siblings, and school-home distance.

Nowadays, public schools in Indonesia adopt zone-based system. This system is similar with the mandatory model. Schools prioritize students from the same zone in the acceptance process. The goal is also the same, which is 
allocating students to the school that is near them. The second goal is to eliminate segregation among public schools which discriminate public schools into two terms: favourite schools and non-favourite schools [7]. This goal is tried to be achieved by eliminating student's national exam score from the selection criteria. In the previous era, student's national exam score was the main criterion in the selection process [7]. Students with high national exam score competed to apply to the favourite schools. In the end, favourite schools were attended by the high performing students while non-favourite schools were attended by the low performing students [17]. It made competition occurs only among favourite schools. Based on their low intake, it was almost impossible for the nonfavourite schools to compete [7].

Moreover, the exam-score based selection was also blamed in generating segregation among students based on the family income level [7]. Several studies showed that there is proportional relation between family income and student academic achievement. Students from high family income have more privilege and support to improve their academic achievement [3]. For example, they can take expensive additional academic course to support their performance at school. The opposite condition, although it is not always, happens to the students from the low family income. In the end, the students from the higher income family tend to achieve better national exam score compared with the students from the lower income family [17].

Based on this problem, government of Indonesia has announced policy for every public school to allocate certain minimum quota for poor students. This policy is called affirmative channel [1]. In many cases, in this channel, student national exam score and/or student school-home distance were excluded in the selection criteria. As far as these students can show legal poor family certificate, they can be accepted in any public schools, even in the favourite schools. Also in many cases, the quota of the affirmative channel can surpass the quota of the academic achievement channel. Moreover, in some cases, this policy triggers fraud where many applicants come with fake poor family certificate because the affirmative channel is easier than the regular zone-based channel or academic achievement channel in securing seat in the favourite school.

In Indonesia, the selection process occurs in several sessions [9]. The regular zone-based channel and affirmative channel usually occurs earlier. The academic achievement channel usually occurs last if there are some available seats. Students that are rejected from the previous channel can propose for the next channel. In several places, the zone-based system is interpreted as the applicants are sorted based on the school-home distance and the student national exam score are excluded. Different implementation of the zone-based system also occurs in the different districts. School-home distance is converted into several classes with discrete score [1]. Students are sorted based on the accumulation of the national exam score and the school-home distance score. Applicants can choose one or more schools. If they are rejected from their preferred schools, then they fail in attending public schools. This process may create mismatch.
The simpler mechanism is implemented for example in the New York city [14]. The selection or matching process adopts the deferred-acceptance algorithm [15]. Students can choose up to some schools as their preference. Then, the selection runs in two rounds. In the first round, system will try to allocate the applicants based on their choices [14]. The students' preference is then matched with the schools' preference. The students who are rejected in the first round then go to the second round. In the second round, the students will be allocated to the school as near as possible to their home [14]. This mechanism accommodates both school choice and zone-based models. This system also has advantage in minimizing the mismatch. In the over-supply or equal supplydemand condition, all applicants are guaranteed to be assigned.

This deferred-acceptance algorithm is a derivative of the stable marriage algorithm which was introduced by Gale and Shapley [11]. This algorithm is popular and widely implemented. This algorithm works to match between two groups. The first group acts as the proposal submitter and the second group acts as the proposal evaluator. In its origin, there are two groups: men and women. The process of the algorithm is as follows [10]:

1) In the beginning, every man submits proposal to his most preferred woman. Some women may receive some proposals while some women do not receive proposal.

2) Then, every woman who receives proposals will choose the man whom she prefers most. Other proposals will be declined. Every man whose proposal is accepted becomes engaged.

3) Every unengaged man then submits new proposal to his most preferred woman in the rank, but first, he must exclude women whom he has sent proposal to in the previous time from his list.

4) Every woman who receives proposal or proposals then selects the men, including whom she currently engages with. She accepts the most current preferred men and declines the others.

5) In the condition of equal number of men and women, the process ends after the last woman receives and accepts proposal. In other word, the process ends after there is no more rejection.

In the scenario where men become submitters, it is called as male-optimal solution [20]. It is because men have better opportunity to engage with his most preferred woman. The men's satisfaction decreases only when they are rejected so that they must submit to the other women. In the other side, women can improve their satisfaction only when they receive better proposal in the future rounds. This scenario is interchangeable so that it is called as female-optimal solution [20].

This one-to-one matching is easily transformed into manyto-one matching as it was conducted by Gale and Shapley [10] in the college admission or by Abdulkadiroglu [21] in the school admission. As a school or college has quota, then students who are submit to a school will be sorted based on 
the school's preference. Students who are inside the quota will be temporarily engaged while students who are outside the quota will be permanently unengaged to this school. In the scenario where the students submit the proposal then it is called as student-dominant scenario [21]. This condition is also interchangeable so that it is called as school-dominant scenario [21].

Based on this explanation, the stable marriage algorithm or deferred-acceptance algorithm is potential to be adopted in developing student selection model in Indonesia that meets the stakeholders' (student, family, and government) interest and eliminating the mismatch. Meanwhile, this algorithm must be improved first so that it can meet the requirement. Moreover, due to the autonomy in every district government, the proposed model must be easily adjusted because prioritization may be different among district governments.

\section{PROPOSED MODEL}

The proposed admission model consists of students and schools [10]. In this model, the students act as the proposal submitters so that this model is called as student-optimal model [21]. Meanwhile, the schools act as proposal evaluators so that schools can accept or reject the incoming proposals. Every school has their own quota [10]. There are some students' concerned parameters and schools concerned parameters. Similar with the previous work [14], every student can choose some preferred schools. It means, the school choice is accommodated in this model [16]. The prioritization among parameters can be different. Before we explain the proposed model further, first we explain that all notations that are used in the mathematical model are described in the nomenclature section.

There are several notations that are used in this proposed model. These notations are as follows:

$i$
$j$
$k$
$n_{a}$
$n_{s}$
$n_{p a}$
$n_{p s}$
$q_{j}$
$s_{a, k, i}$
$s_{s, k, j}$
$s_{a m i n, j, k}$
$s_{a m a x, j, k}$
$s_{s m i n, i, k}$
$s_{s m a x, i, k}$
$s_{a n, i, j, k}$
$s_{s n, i, j, k}$
$s_{t a, i, j}$
$s_{t s, i, j}$
$S_{p r, j}(t)$
$S_{p a, i}(t)$
$S_{p s, i}(t)$
$t$
$w_{a, k}$
$w_{s, k}$

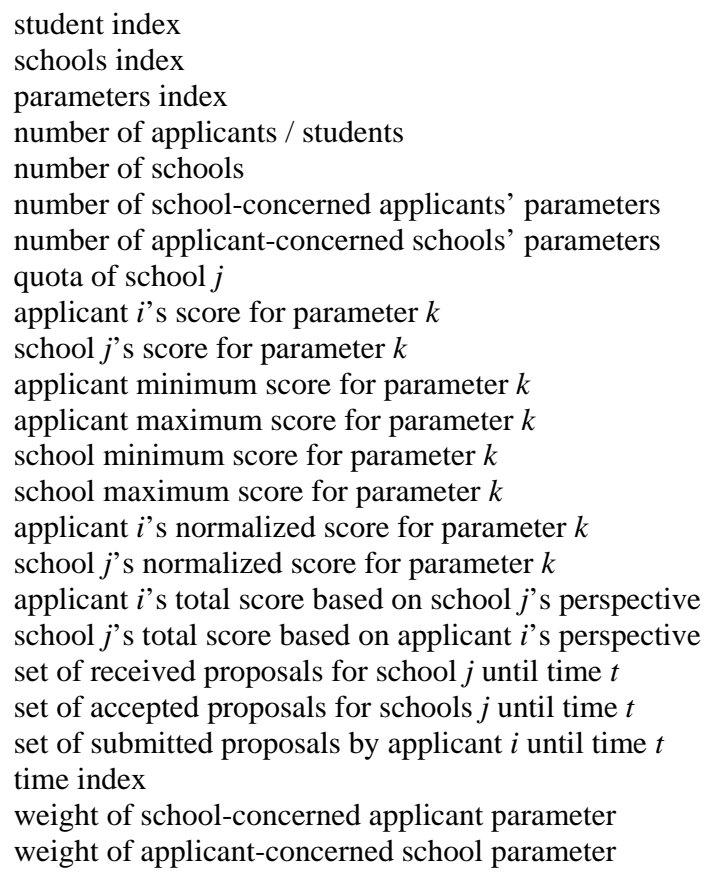

Decision taken by both applicants and schools is determined based on the total score of the opponents. Selected school that the applicant will submit to at time $t$ is determined by using (1). Meanwhile, set of applicants that are accepted until time $t$ is determined by using (2). In (2), it is shown that the accepted applicants until time $t$ is determined by sorting the received proposals from the highest to the lowest based on the applicants' total score and they are taken up to the school quota [10].

$$
\begin{aligned}
& \operatorname{sel}_{s, i}(t)=j, \max \left(s_{t s, i, j}(t)\right) \wedge j \notin S_{p s, i}(t-1) \\
& S_{p a, j}(t)=\text { sort_descending }\left(S_{p r, j}(t), s_{t a, i, j}(t), q_{j}\right)
\end{aligned}
$$

The total score, both in the applicant's score and the school's score, is the accumulation of the weighted scores. By augmenting the weight in every parameter score, it is easily to set which parameters are more important and which ones are less important. This weighing concept is similar with the previous work that accommodated multiple parameters [22]. More weight to be augmented in some parameters means more important these parameters are [22]. The applicant's total score is calculated by using (3) while the school's total score is calculated by using (4).

$s_{t a, i, j}(t)=\sum_{k=1}^{n_{p a}}\left(w_{a, k} \cdot s_{a n, i, k}(t)\right)$
$s_{t s, i, j}(t)=\sum_{k=1}^{n_{p s}}\left(w_{s, k} \cdot s_{s n, i, k}(t)\right)$

Each score, before it is calculated with the weight, will be normalized first. In this work, the min-max normalization method is used [23]. It ranges from 0 to 1 . The reason in normalizing this score is because every parameter uses its own metric. For example, applicant's national exam score ranges from 0 to 100 . School-home distance is in meter or any other distance units. The applicant's poor status is 0 or 1 . Based on it, normalized score is used so that all scores are comparable to each other. If the value of the parameters is proportional to the score, such as student poor status [1] or national exam score [7], then the applicant's normalized score is calculated by using (5) while the school's normalized score is calculated by using (6). In the other side, if the value of the parameters is inversely proportional to the score, such as school-home distance [17] or school rank, then the applicant's normalized score is calculated by using (7) while the school's normalized score is calculated by using (8). To determine the normalized score, the minimum and maximum scores in the set are used.

$$
\begin{aligned}
& s_{a n, i, j, k}(t)= \\
& \left\{\begin{array}{c}
\frac{s_{a, k, i}-s_{a \min , j, k}(t)}{s_{\text {amax }, j k}(t)-s_{a \min , j, k}(t)}, s_{\text {amax }, j, k}(t) \neq s_{\text {amin }, j, k}(t) \\
1, s_{\text {amax }, j, k}(t)=s_{a \min , j, k}(t)
\end{array}\right. \\
& s_{s n, i, j, k}(t)=\left\{\begin{array}{c}
\frac{s_{s, k, j}-s_{\text {smin }, i, k}(t)}{s_{\text {smax }, i, k}(t)-s_{\text {smin }, i, k}(t)}, s_{\text {Smax }, i, k}(t) \neq s_{\text {smin }, i, k}(t) \\
1, s_{\text {smax }, i, k}(t)=s_{\text {smin }, i, k}(t)
\end{array}\right. \\
& s_{a n, i, j k}(t)= \\
& \left\{\begin{array}{c}
1-\frac{s_{a, k, i}-s_{a \min , j, k}(t)}{s_{a \max , j, k}(t)-s_{a \min , j, k}(t)}, s_{\text {amax }, j, k}(t) \neq s_{a \min , j, k}(t) \\
1, s_{\text {amax }, j, k}(t)=s_{a \min , j, k}(t)
\end{array}\right.
\end{aligned}
$$


$s_{s n, i, j, k}(t)=$

$\left\{\begin{array}{c}1-\frac{s_{s, k, j}-s_{\text {smin }, i, k}(t)}{s_{\text {smax }, i, k}(t)-s_{\text {smin }, i, k}(t)}, s_{\text {smax }, i, k}(t) \neq s_{\text {smin }, i, k}(t) \\ 1, s_{\text {smax }, i, k}(t)=s_{\text {smin }, i, k}(t)\end{array}\right.$

The minimum and maximum score is determined as follows. The applicant's minimum and maximum scores are compared among applicants that is submitting proposals to the school $j$ plus applicants in the school $j$ 's quota. In the other side, the school's minimum and maximum scores are compared among schools that has not been submitted by the applicant $i$. The applicant minimum and maximum scores are determined by using (9) and (10). The school minimum and maximum scores are determined by using (11) and (12).

$s_{a \operatorname{amin}, j, k}(t)=\min \left(s_{a, i, k}\right) \wedge i \in S_{p r, j}(t)$
$s_{a \operatorname{amax}, j, k}(t)=\min \left(s_{a, i, k}\right) \wedge i \in S_{p r, j}(t)$
$s_{s \min , i, k}=\min \left(s_{s, j, k}\right) \wedge j \notin S_{p s, i}(t-1)$
$s_{s \max , i, k}=\min \left(s_{s, j, k}\right) \wedge j \notin S_{p s, i}(t-1)$

\section{Simulation RESUlT}

This proposed model is then implemented into the student admission simulation. This simulation is a coordinated school admission which consists of schools and applicants. The simulation is based on the senior high school admission system. The schools are public schools. The environment is Yogyakarta city in Indonesia. This city size is approximately $46 \mathrm{~km}^{2}$. There are eleven public senior high schools in Yogyakarta. In this simulation, the quota of every school is assumed equal, which is 100 students so that the total quota is 1,100 students. In this work, the students' home location and schools' location are distributed uniformly in the city. The student's national exam score is distributed normally with the mean is 80 and standard deviation is 10 .

There are some concerned parameters by the applicants and the schools. The applicant-concerned parameters are school rank, applicant's preference [1], and school-home distance [7]. Meanwhile, the school-concerned parameters are national exam score [1], school-home distance [7], and poor status [1]. In the default condition, weight of all these parameters is set 0.5 . It means that all parameters are equally prioritized.

There are three simulations and three observed parameters. These three observed parameters are average student's schoolhome distance, average student's national exam score, and number of accepted applicants. The first and second parameters are observed in the first and second simulation. The third parameter is observed in the third simulation. The average student's school-home distance is observed because it is the important determinant in both the zone-based model [7] and in the school choice model, specifically in the two-step model [14]. The average student national exam score is observed because it is a relatively concerned parameter by the stakeholders who concern in competition. The number of accepted applicants is observed to evaluate whether there is mismatch in the admission process. These first two parameters are evaluated based on the accepted students. The first simulation is to observe the relation between the number of applicants and the first two observed parameters. The second simulation is to observe the relation between the national exam score-school rank and student national exam score weights; and the first two observed parameters. In the first simulation, the performance of the proposed model is compared with the previous works: the zone-based model [7] and the two-step model [14]. In the first simulation, the number of students ranges from 1,100 to 2,200 students. In the second simulation, the national exam score and school rank weights range from 0.1 to 0.9 . In the second simulation, the number of applicants is 2,200 persons. In the third simulation, the number of applicants ranges from 220 to 2,200 students which represents from over-supply to over-demand condition.

Now, we will discuss the simulation result. The result of the first, second, and third simulations is shown in Fig. 1, Fig. 2, and Fig. 3, consecutively. In Fig. 1, zoning represents the zone-based model [7], two-step represents the two-step model [14], and SM represents the proposed stable marriagebased model.

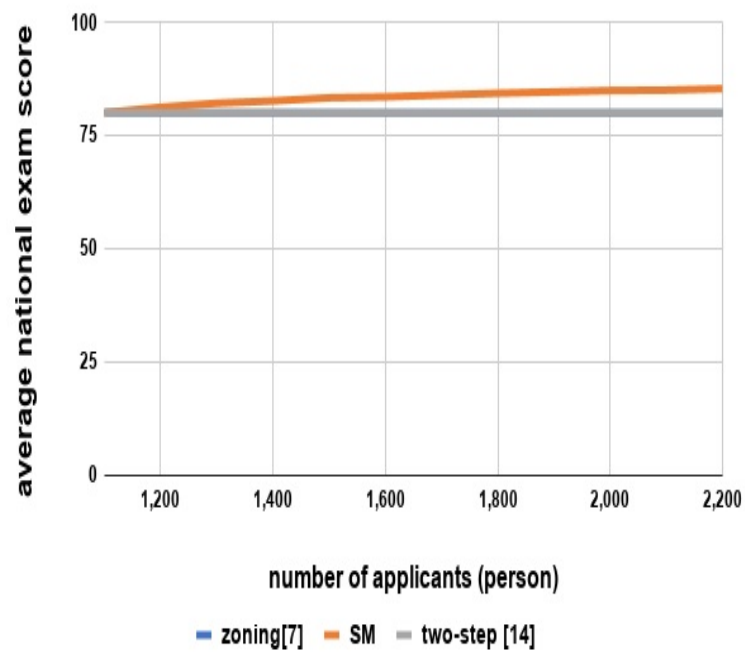

(a)

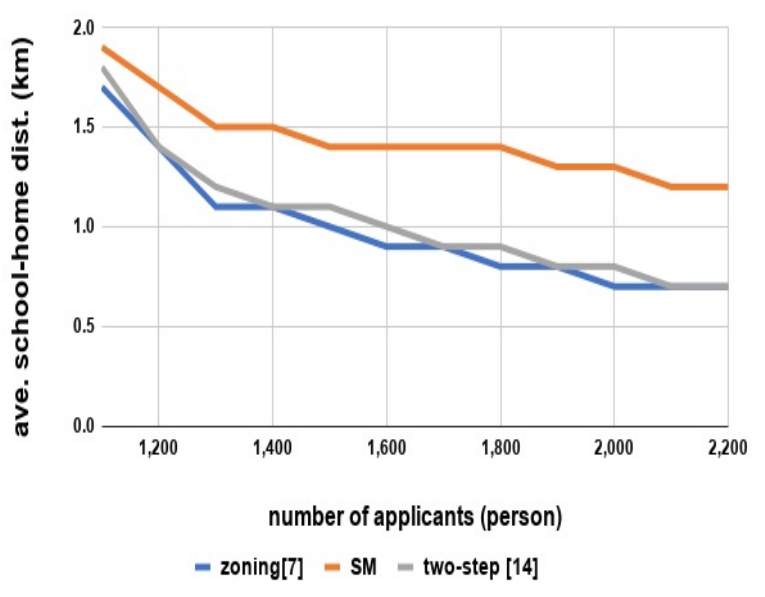

(b)

Fig. 1. Number of Applicants vs. Observed Parameters: (a) Average National Exam Score (b) Average School-Home Distance. 
The explanation of the result in Fig. 1(a) is as follows. When the system implements zone-based model [7] or the two-step model [14], the increasing of the number of applicants does not affects the average national exam score of the accepted students. Meanwhile, when the system implements the stable marriage model, the increasing of the number or applicants makes the average national exam score increases. In the beginning, the inclination is high. Meanwhile, it goes lower due to the increasing of the number of applicants. In the beginning, in the equal supply-demand condition, all models perform equally. In the extreme overdemand condition, when the number of applicants is twice of the total quota, the average national exam score of the accepted students of the proposed model is 6.6 per cent higher than the previous models $[7,14]$. Based on this explanation, it is proven that this proposed model accommodates the academic competition among the applicants [16].

In Fig. 1(b), it is shown that the average school-home distance decreases due to the increasing of the number of applicants. It happens in all models. The average school-home distance of the previous models $[7,14]$ tends to be equal. Meanwhile, the average school-home distance of the stable marriage model is the highest among models. In the beginning, due to equal supply-demand condition, the gap between the stable marriage model and the previous models is narrow. This gap becomes wider due to the increasing of the number of applicants. In the extreme over-demand condition, when the number of applicants is twice of the total quota, the average school-home distance of the stable marriage model is 71.4 per cent higher than the previous models. Based on this explanation, it is proven that this model accommodates the concern in reducing the school-home distance [17].

The explanation of the second simulation is as follows. Result in Fig. 2(a) shows that in the over-demand condition, when the school rank and student national exam score weights are low (0.1), the average national exam score of the accepted students is a little bit higher than the average national exam score of all applicants. In the other side, when these weights are set high (0.9), the average national exam score of the accepted applicants is 7.7 per cent higher than all applicants. The result in Fig. 2(b) shows that in the over-demand condition, the average school-home distance increases due to the increasing of these weights. When these weights are set low (0.1), the average school-home distance is $0.8 \mathrm{~km}$ and when these weights are set high (0.9), the average schoolhome distance is $1.7 \mathrm{~km}$ or 112.5 per cent higher.

In Fig. 3, it is shown that the proposed model has solved the mismatch problem in the admission process. When the number of applicants ranges from 220 persons to 1,100 persons, which is from over-supply to equal supply-demand condition, the number of the accepted applicants is equal to the number of applicants. It means that all applicants are accepted and there is no rejection. After that, when the number of applicants ranges from 2,320 persons to 2,200 persons, which is over-demand condition, the number of accepted applicants is still 1,100 persons or it is same as the total quota.

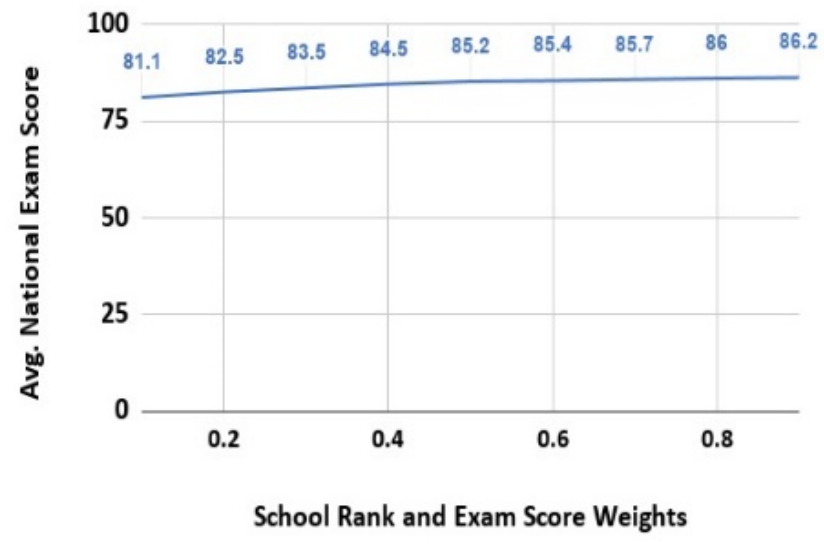

(a)

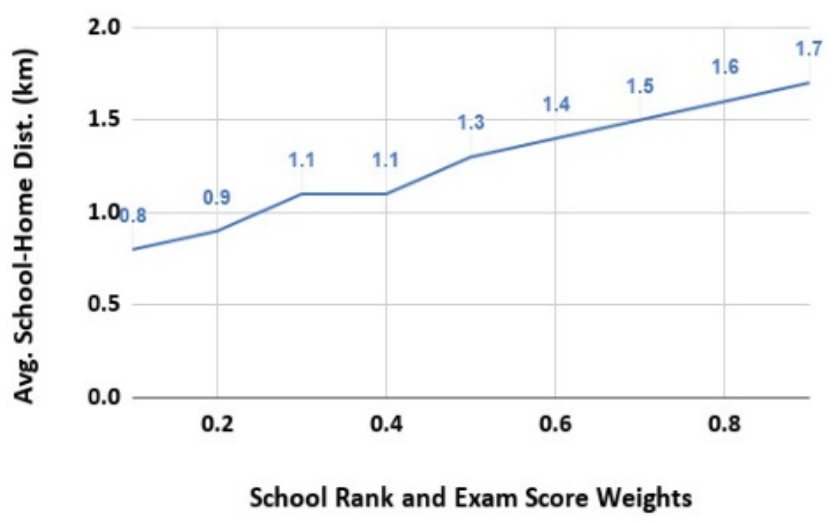

(b)

Fig. 2. School Rank and Exam Score Weights vs. Observed Parameters: (a) Average National Exam Score (b) Average School-Home Distance.

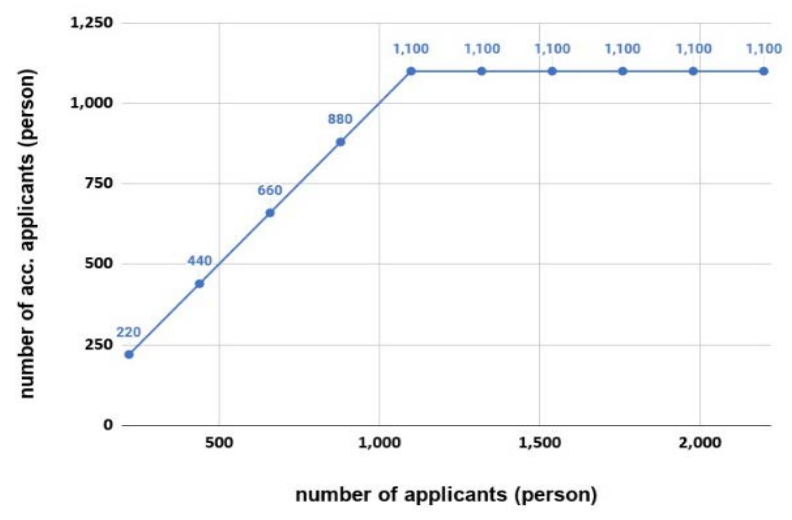

Fig. 3. Number of Applicants vs. Number of Accepted Applicants.

\section{Discussion}

There are several findings due to this simulation result. It is shown that, compared with the previous models, both the zone-based model [7] and the two-step model [14], the proposed model achieves the highest one in minimizing the school-home distance. This gap becomes wider in the over- 
demand condition. The reason is that the school-home distance is not the only concerned aspect in this model. It is different from the previous models which focus on the schoolhome distance. Fortunately, this proposed model performs as the best model in achieving the highest average student national exam score although the different is not high. Once again, it is because the student national exam score is also not the only concerned parameter in this proposed model.

Based on this explanation, it can be said that this model can compromise all concerned parameters (school-home distance [17], competition [19], equality [9], affirmative [1], and preference/choice [16]). It is also shown that by using this model, the process becomes simpler because all parameters are calculated together in a single process, and they are easily adjusted due to the stakeholders' interest. It is different from the previous models $[7,14]$ where the process is divided into multiple sessions, and they run sequentially. It is also shown that the model guarantees that all applicants will be accepted when there are available seats in the system or in the oversupply to equal demand-supply condition. It means that the mismatch is eliminated.

\section{CONCLUSION}

A coordinated stable marriage-based student admission model has been developed and it accommodates multi concerned parameters in both schools and applicants. This model has also been implemented in the student admission simulation so that its performance can be analysed and compared with the previous models (zone based and two-step models). Based on the observations of the simulation result, some concluding observations are given below.

- The proposed model is proven in solving the mismatch problem in the school admission process.

- In the over-supply to equal supply-demand condition, the average student national exam score of the proposed model is equal with the previous models. In the over-demand condition, the average student national exam score of the proposed model is higher than the previous model. In the condition where the number of applicants is twice of the number of seats, the average student national exam score of the proposed model is 6.6 per cent higher than the previous models.

- The average school-home distance of the proposed model is higher than the previous models. The gap of it is wider due to the increasing of the demand. When the number of applicants is twice of the number of seats, the average school-home distance of the proposed model is 71.4 per cent higher than the previous models.

The prioritization of the concerned parameters is proven easily adjusted by manipulating the weights. When the number of applicants is twice of the number of seats, the high school rank and student exam score weights (0.9) perform 7.7 per cent higher in the average student national exam score and 112.5 per cent higher in the average school-home distance compared with the low weights (0.1).
There are several future research potentials due to this work. This work has proposed the coordinated based model. This work can be modified to become autonomous or semiautonomous model where each school has better independency. In this model, all parameters are treated parallelly. Meanwhile, in some regulation, some parameters become requirement for other parameters so that a decisiontree based model can be used to improve the model that is proposed in this work.

\section{ACKNOWLEDGMENT}

This work was supported by Telkom University, Indonesia.

\section{REFERENCES}

[1] Sularto, Wahyudi, and Sukmawati, "The admission of the new students based on online system at SMAN 2 Singkawang”, Journal of Education, Teaching, and Learning, vol. 3, no. 2, pp. 336-341, 2018.

[2] A. Abdulkadiroglu, Y. K. Che, and Y. Yasuda, "Expanding choice in school choice”, American Economic Journal: Microeconomics, vol. 7, no. 1, pp. 1-42, 2015.

[3] D. Kessel, "School choice, school performance and school segregation", dissertation. Stockholm University, Stockholm, 2018.

[4] C. M. D. Hart and D. N. Figalo, "School accountability and school choice: effect on student selection across schools", National Tax Journal, vol. 68, no. 3S, pp. 875-900, 2015.

[5] A. Hofflinger, D. Gelber, and S. T. Canas, "School choice and parents' preferences for school attributes in Chile", Economics of Education Review, vol. 74, article ID: 101946, 2020.

[6] H. H. Erickson, "How do parents choose schools, and what schools do they choose? A literature review of private school schoice programs in the United States”, Journal of School Choice, vol. 11, no. 4, pp. 491506, 2017.

[7] Y. Sulistyosari, S. I. A. Dwiningrum, N. Q. A. Zummi, S. W. Tomo, and D. Indrahadi, "Examining the basic educational rights in the newly implemented school zoning policy in Indonesia”, Proceedings of the $2^{\text {nd }}$ International Conference on Social Science and Character Education (ICoSSCE), Yogyakarta, Indonesia, 2019.

[8] Suryanto and Komary, "The implementation of school zonation system in Yogyakarta”, Proceedings of the $3^{\text {rd }}$ International Conference on Sustainable Innovation 2019-Humanity, Education, and Social Science (IcoSIHESS), Yogyakarta, Indonesia, 2019.

[9] K. A. B. Bakar, Y. Supriyati, and I. Hanafi, "Evaluation of admission student policy based on zoning system for acceleration education quality in Indonesia”, Journal of Management Info, vol. 6, no. 2, pp. 19-24, 2019.

[10] D. Gale, and L. Shapley, "College admissions and the stability of marriage”, American Mathematical Monthly, vol. 69, no. 1, pp. 9-15, 1962.

[11] P. Dworczak, "Deferred acceptance with compensation chains", Operations Research, vol. 69, no. 2, pp. 456-468, 2020.

[12] A. F. M. S. Saif, M. Rashid, I. Z. Bhuiyan, M. W. S. Ifty, and M. R. Sarker, "Stable marriage algorithm for student-college matching with quota constraints", Proceedings of the International Conference on Computing Advancements (ICCA), Dhaka, Bangladesh, 2020.

[13] M. Mnich and I. Schlotter, "Stable matchings with covering constraints: a complete computational trichotomy”, Algorithmica, vol. 82, pp. 11361188, 2020.

[14] A. Abdulkadiroglu, N. Agarwal, and P. A. Pathak, "The welfare effects of coordinated assignment: evidence from the New York City high school match”, American Economic Review, vol. 107, no. 12, pp. 36353689, 2017.

[15] F. Klijn, J. Pais, and M. Vorsatz, "Improving schools through school choice: an experimental study of deferred-acceptance", Economic Letters, vol. 186, article ID: 108853, 2020. 
[16] A. Abdulkadiroglu, P. A. Pathak, J. Schellenberg, and C. R. Walters, "Do parents value school effectiveness", working paper, Cambridge, 2019.

[17] Martifah, "Zoning system of education as a strategy for equalizing education quality in the disruptive era (legal aspect review)", Proceedings of the $1^{\text {st }}$ International Conference on Education, Social Sciences, and Humanities (ICESSHum) 2019, Padang, Indonesia, 2019.

[18] M. Bertoni, S. Gibbons, and O. Silva, "School choice during a period of radical school reform: evidence from the academy programme”, IZA discussion paper, no. 11162, 2017.

[19] P. Hennerdal, B. Malmberg, and E. K. Andersson, "Competition and school performance: Swedish school leavers from 1991-2012”, Scandinavian Journal of Educational Research, vol. 64, no. 1, pp. 70-86, 2020.
[20] D. Zivkovic, “A note on the stable marriage problem”, SN Computer Science, vol. 1, article ID: 115, pp. 1-4, 2020.

[21] A. Abdulkadiroglu and T. Sonmez, "Matching market: theory and practice”, Advances in Economics and Econometrics: Tenth World Congress. Cambridge University Press. Cambridge, 2013.

[22] P. D. Kusuma and H. U. Mustakim, "Multi parameter high school student admission system", Journal of Engineering and Applied Sciences, vol. 14, no. 15, pp. 5258-5266, 2019.

[23] H. Benhar, A. Idri., and J. L. Fernandez-Aleman, "Data preprocessing for heart disease classification: a systematic literature review", Computer Methods and Programs in Biomedicine, vol. 195, article ID: 105635, 2020. 